\title{
PORTUGUÊS PARA ESTRANGEIROS A DISTÂNCIA: UMA EXPERIÊNCIA DO CELIN/UFPR
}

Distance Learning Portuguese as a Foreign Language: an experience at Celin - UFPR

\author{
Lygia Maria Leite SALTINI - Celin/UFPR ${ }^{1}$ \\ Maria Fernanda Araújo LISBOA - FACINTER/UFPR ${ }^{2}$ \\ Roberta Rafaela Sotero COSTA - FACEL/UFPR ${ }^{3}$ \\ Sandra Lopes MONTEIRO - UFPR $^{4}$
}

\begin{abstract}
RESUMO: O curso de português para estrangeiros a distância do Celin/UFPR é uma proposta direcionada ao desenvolvimento e ampliação do conhecimento linguísticodiscursivo baseado na concepção bakhtiniana de língua como prática social. Seu principal objetivo é oportunizar ao estudante estrangeiro o acesso à produção de textos de diferentes gêneros para o qual devem ser abordados tópicos gramaticais, socioculturais e pragmáticos. A temática e as tarefas propostas no decorrer das unidades do curso consideram o aprendente como um ator social e procuram fornecer subsídios linguísticos e culturais visando a competência comunicativa. Ao longo do curso, os alunos serão levados à reflexão sobre a sua língua nativa e sua(s) cultura(s) para que conheçam a cultura brasileira e percebam, com um novo olhar, a sua própria cultura. Durante o curso são propostos diversos gêneros textuais e a cada unidade o grau de complexidade gramatical e de textos orais e escritos aumenta gradativamente, partindo das necessidades básicas de comunicação e de interação social para, depois, falar de seu entorno, seu país e a cultura do outro.
\end{abstract}

PALAVRAS-CHAVE: Português Língua Estrangeira; EaD; Análise do Discurso; Gêneros Textuais

ABSTRACT: The Distance Learning Course in Portuguese as a Foreign Language at Celin - Language and Intercultural Centre at UFPR - Federal University of Paraná, Brazil, is a proposal to develop and increase the linguistic-discursive knowledge based on Bakhtin's conception of language as social practice. Its main objective is to provide the students with the opportunity to meet and produce different textual genres which will take them to the analysis of grammatical, social-cultural and pragmatic topics. The themes and activities proposed inside the course units consider the learner a social actor and aim at providing the linguistic and cultural tools to achieve communicative competence. Throughout the course, learners will be provoked to think about their own languages within their cultures in order to learn about the Brazilian culture and, with a new view,

\footnotetext{
${ }^{1}$ Celin - UFPR.

${ }^{2}$ Professora de Português como Língua Estrangeira. FACINTER e UFPR.

${ }^{3}$ Professora de Português como Língua Estrangeira. FACEL e UFPR.

${ }^{4}$ Professora do DELEM - UFPR.
} 
look back at their cultures. During the course, different textual genres are presented and the complexity of grammar, oral and written texts is increased, going from basic communication needs to social interaction leading to competence to speak about their surroundings, their countries and one another's culture.

KEY WORDS: Portuguese as a Foreign Language; Distance Learning; Discoursive Analysis; Textual Genres

\section{Descrição do Celin e as Atividades de PLE}

O Centro de Línguas e Interculturalidade, criado em 1995, é um espaço de prática docente para os alunos de Letras da Universidade Federal do Paraná. Desde a sua criação uma das metas do seu Programa de Extensão - "Espaço Integrado para Ensino e Aprendizagem, Pesquisa e Formação de Professores de Línguas e Culturas Diversas" é a de oferecer à comunidade interna e externa à UFPR cursos de línguas estrangeiras ministrados por professores com formação em Letras. Entre os cursos ofertados pelo Celin, temos o de Português como Língua Estrangeira - PLE para atender o grande número de estrangeiros que chegam na cidade de Curitiba e, sobretudo, os alunos do programa de mobilidade acadêmica de universidades estrangeiras, procedentes de diferentes países, que precisam dominar o português para acompanharem atividades acadêmicas na Universidade Federal do Paraná ou outra instituição de ensino superior no Brasil. Há grupos de profissionais que precisam não só dominar a língua portuguesa, mas também obter a certificação expedida pelo governo brasileiro através do exame Celpe-Bras, condição sine qua non para revalidação de seus títulos de graduação e pós-graduação no Brasil.

O Português como Língua Estrangeira ${ }^{5}$ cresce na instituição, organiza-se de forma a produzir o próprio material a ser utilizado nos cursos, estabelece convênios com universidades estrangeiras que procuram por cursos de português como língua estrangeira em imersão e mantém a oferta de formações continuadas aos seus professores e estagiários. O público alvo do curso de PLE é bastante variado: estrangeiros que trabalham em Curitiba, intercambistas, alunos estrangeiros que estudam em imersão na modalidade intensiva e executivos que vêm trabalhar no Brasil e precisam de uma formação em Português como Língua Estrangeira.

\footnotetext{
5 A partir da constatação de que as atividades propostas pelo Celpe-Bras são relevantes para o processo de aquisição de Português como Língua Estrangeira e da necessidade de se rever os programas e atividades propostos pelo Celin, decidiu-se elaborar atividades contemplando tanto o desempenho oral quanto escrito que pudessem servir de base para candidatos em potencial para o exame.
} 
Com o processo de internacionalização da UFPR que hoje mantém acordos de cooperação e convênios com mais de noventa universidades em todo o mundo, a Assessoria de Relações Internacionais da UFPR - ARI estabeleceu parceria com o Celin de forma a oferecer o Curso de Português como Língua Estrangeira a todos os alunos que vêm estudar em nossa Universidade, inclusive os alunos do Programa Estudante Convênio de Graduação - Pec-G que seguem os cursos de PLE antes de ingressarem na graduação em uma universidade brasileira. A disciplina de PLE está contemplada no currículo do aluno intercambista e tem controle de nota e frequência. Para os alunos Pec-G a meta é obter a certificação brasileira Celpe-Bras para ter o direito de ingressar na universidade. Estes alunos estudam português no Celin com o objetivo de dominar a língua em suas quatro competências (compreensão oral e escrita, expressão oral e escrita) para acompanhar cursos de graduação e pós-graduação na UFPR ou em outras instituições da mesma natureza. Já os alunos estrangeiros em férias no Brasil visam estudar o português em imersão para, ao retornar aos seus países de origem, dominar mais uma língua além da língua materna.

O crescente desenvolvimento do Brasil na área econômica tem atraído, sobretudo, profissionais de comércio exterior para aprender a língua portuguesa falada no Brasil. Com o objetivo de manter relações comerciais com empresas brasileiras ou estabelecer suas empresas no Brasil, esses profissionais buscam cursos de língua portuguesa na modalidade presencial ou a distância para, em dominando o idioma, fomentar negócios praticamente inexistentes no mercado brasileiro. Entre este público, encontram-se também senhoras estrangeiras que acompanham seus maridos em viagens de negócio ao Brasil e necessitam do PLE para sobreviver de forma adequada na sociedade paranaense.

Proposta do Curso de PLE a Distância (resultado do acordo de cooperação estabelecido entre a Universidade Federal do Paraná e a Université Stendhal - Grenoble / França)

Mais recentemente, com o acordo de cooperação estabelecido entre a Universidade Federal do Paraná e a Université Stendhal - Grenoble/França foi criado, em 2010, o projeto Coopera que tem, entre os seus objetivos ${ }^{6}$, o de desenvolver em parceria com o

\footnotetext{
${ }^{6}$ Entre outros objetivos, o projeto Coopera prevê uma estreita cooperação entre a Universidade Federal do Paraná, a Universidade de Grenoble e o Centro de Línguas e Interculturalidade da UFPR para ensino do português como língua estrangeira, para o desenvolvimento de pesquisas voltadas às ciências da linguagem, à
} 
Celin o curso de português língua estrangeira a distância. Ao Celin cabe o desenvolvimento do curso e à Université Stendhal as adaptações às tecnologias de comunicação e informação - TICs. A criação dessa modalidade de curso é de responsabilidade do Celin e, de forma piloto, será ofertado a universitários franceses que concluirão o mestrado em Letras na UFPR. Está previsto no referido acordo que o Curso de Pós-Graduação em Letras e o da Université Stendhal expedirão aos alunos concluintes do mestrado a dupla diplomação.

Há alguns anos considera-se a necessidade de criação de um curso a distância de português para estrangeiros, visando antecipar o aprendizado da língua antes de sua chegada ao Brasil. Tal iniciativa facilita, de um lado, o ingresso na vida acadêmica de alunos provenientes de Universidades estrangeiras que mantêm convênio com a UFPR para realizar estudos de graduação ou de pós-graduação; de outro, uma melhor integração daqueles que já iniciaram seus estudos em suas universidades de origem e buscam em instituições estrangeiras a complementação de suas formações. Essa aprendizagem não se encerra no curso a distância, mas deve ser complementada durante o tempo do intercâmbio do aluno pelo curso presencial de português para estrangeiros (PLE) ofertado pelo CelinUFPR. Além disso, muitos alunos que estudam no Celin e voltam para seus países, continuam mantendo contato com alguns professores e já demonstraram interesse em continuar estudando português via internet.

Diante do diversificado público que busca aprender o PLE no Celin ${ }^{7}$, é importante ressaltar que a instituição não tem como absorver a totalidade desses alunos de forma presencial, principalmente pela restrição de horários e espaço físico. Tendo em vista que a demanda pelo ensino do PLE na modalidade presencial tem aumentado a cada ano, seja para os cursos intensivos como extensivos, o Celin tem buscado alternativas para atender essa procura. Uma das possibilidades levantada foi a de elaboração de um curso de PLE na modalidade a distância, solicitado, formalmente, por países como a França, o Canadá, o Líbano e a ARI/UFPR através de correspondência. Esta solicitação nasceu da necessidade deste público tão variado chegar ao Brasil já com algum conhecimento inicial da língua portuguesa, concluir o aprendizado do PLE e dar continuidade em seus países de origem ao

didática, à formação de professores e à utilização das TICs no ensino do português como língua estrangeira a distância.

${ }^{7}$ A cada ano, o Celin atende, em média, 300 alunos estrangeiros. Dentre eles, os que mais nos procuram são franceses, italianos, latino-americanos, americanos, coreanos, japoneses etc. 
aprendizado desta língua. Essa modalidade possibilita ainda aos intercambistas que estudam na UFPR aprender o português na modalidade a distância de forma que este curso não interfira na grade horária da graduação e pós-graduação.

Para se chegar à opção pelo ensino a distância, foi investigado o processo de construção do curso, seu impacto na formação dos professores de PLE envolvidos e uma previsão da eficácia do curso. Com esta modalidade, amplia-se o atendimento a um público diferenciado que tem como motivação dominar a língua estrangeira do país onde realizará os seus estudos. Como nem sempre é possível seguir os estudos de línguas estrangeiras em imersão, há um apelo muito grande para que se veicule um curso de qualidade, pensado e realizado por especialistas no ensino do Português como Língua Estrangeira, contando com as contribuições da linguística aplicada ao ensino de línguas e das "novas tecnologias".

Assim, o curso proposto será ofertado inicialmente a estudantes franceses da Université Stendhal como já mencionado e, na sequência, o curso deverá ser aberto a um público geral, acima de 17 anos, que pretende aprender o português como língua estrangeira por diversas razões:

- viajar pelo Brasil;

- manter contato com brasileiros;

- fazer negócios com empresas brasileiras, trabalhar no Brasil em empresas multinacionais, trabalhar em empresas brasileiras fora do Brasil;

- interesse pela cultura brasileira;

- complementação de sua formação educacional ou profissional;

- continuar estudando português no seu país, depois de ter tido uma experiência de estudos ou vivência no Brasil;

- morar no Brasil com o objetivo de desenvolver trabalho voluntário ou religioso;

- estabelecer residência no Brasil por alguma razão pessoal ou profissional, e

- por curiosidade, entre outros. 


\section{Elaboração e Estrutura do Curso de PLE a Distância do Celin/UFPR}

Para a elaboração do referido curso, além de um diagnóstico prévio visando certificar-se do interesse ou não do curso, sua viabilização ou não, realizou-se: 1) um levantamento bibliográfico, na tentativa de construir parâmetros para operacionalizar teórica e metodologicamente a produção do curso; 2) um levantamento do conteúdo a ser trabalhado; 3) a organização da estrutura do curso na modalidade a distância; 4) as ferramentas necessárias próprias de ambientes virtuais de aprendizagem que deverão ser utilizadas pelo referido curso, e 5) a avaliação das condições para implementação do curso.

A título de exemplo, apresentamos a estrutura do curso de PLE a distância formatada a partir das investigações. O curso será estruturado em unidades. Cada unidade corresponde a 15 horas, excetuando-se a ambientação que conta com 10 horas de curso. Cada unidade é dividida em três situações de 5 horas cada. O total do curso é de 100 horas. Para atender à especificidade da educação a distância, previu-se que, para as 100 horas efetivas de curso, o aluno dedicará mais 200 horas de trabalho, levando em conta o tempo necessário para questões técnicas da plataforma, acesso a sites complementares para busca de informação, consulta a obras de referência como dicionário, gramáticas e realização das atividades propostas.

Quadro 1: estrutura do curso de PLE a distância do Celin/UFPR

\section{AMBIENTAÇÃO (10h)}

Ambientação no Moodle

Sensibilização à abordagem teórica

Sensibilização sociológica do Brasil

Avaliação/nivelamento

\section{UNIDADE I (15h)}

1.1Primeiros contatos

1.2Cotidiano

1.3Encontros

Avaliação

UNIDADE II (15h)

2.1A cidade

2.2Localização 


\subsection{Moradia}

Avaliação

\section{UNIDADE III (15h)}

\subsection{Compras}

3.2Alimentação

3.3Saúde

Avaliação

\section{UNIDADE IV (15h)}

4.1Qualidade de Vida

4.2Lazer e diversão

4.3Viagens e Turismo

Avaliação

\section{UNIDADE V (15h)}

5.1Fatos passados

5.2 Datas importantes

5.3Trajetórias de Vida

Avaliação

\section{UNIDADE VI (15h)}

6.1Vida profissional e universitária

6.2Relações interpessoais

\subsection{Projetos / planos}

Avaliação

Fonte: as autoras

Para a construção dos cursos de PLE a distância buscou-se subsídios no ensino de línguas estrangeiras através de práticas sociointeracionistas (práticas sociais), na abordagem comunicativa, nos gêneros textuais e no estudo por ação que prevê o ensino/aprendizagem de uma língua estrangeira pela realização de tarefas. O uso dessas teorias contribui para que o curso de PLE a distância assuma um funcionamento sociocomunicativo, socialmente situado, que permitirá o desenvolvimento de uma forma particular de interação: a comunicação dos estrangeiros através do português falado no Brasil.

Com base em princípios teóricos e metodológicos do sóciointeracionismo, a construção desse curso pretende realizar o seu percurso através de incursões por diferentes 
dimensões do funcionamento do gênero. Para o ensino do PLE a distância serão selecionados gêneros textuais pertinentes, privilegiando aqueles que promovem práticas comunicativas e se refletem no processo de textualização da produção oral e escrita. Os gêneros textuais objeto de estudo serão descritos e analisados, observando-se os fatores que intervém no funcionamento específico de determinadas competências linguísticas de forma a contribuir para a produção de uma linguagem socialmente situada e que leve a uma determinada forma de interação.

No universo das práticas de ensino de língua estrangeira que refletem as concepções de texto, de língua, de autor/produtor, de interlocutor, enfim, dos usos da linguagem será necessário dar conta da multiplicidade e heterogeneidade dos textos orais e escritos produzidos na vida cotidiana, em ambiente acadêmico ou mesmo de turismo. Nesse contexto, aprende-se a língua em atividades discursivas reais e concretas que o sujeito pratica no universo social em que está inserido.

Parece evidente que para se apropriar da linguagem oral e escrita em seus processos diversos de funcionamento não basta uma prática qualquer que se dê por meio de um tema qualquer e por indicação de tipos textuais. Essas diferentes práticas da oralidade e da escrita que figuram na sociedade com usos e funções sociais diferentes devem constituir o objeto de aprendizagem de uma língua estrangeira em ambiente formal.

Assim, através da leitura de alguns autores, como Bakhtin, 1990, 1992; Bronckart, 1987; Charaudeau, 2008; Isenberg,1987; Marcuschi, 1995; Petitjean, 1989, entre outros, entendeu-se a importância da inclusão dos gêneros e tipos textuais necessários para o domínio da língua em uso. A princípio não há preferência por um ou outro gênero, uma vez que a intenção maior é a de, exploratoriamente, operar com a teoria dos gêneros e sua aplicação em contexto específico.

\section{Conclusão}

Os estudos sobre o aprendizado de português como língua estrangeira são escassos e, de fato, até mesmo a oferta de cursos dessa modalidade ainda não é expressiva. $\mathrm{O}$ presente trabalho verificou que uma das questões que carece de investigação é como desenvolver a língua estrangeira sem estar em imersão e sem estar frequentando um 
estabelecimento de ensino de línguas estrangeiras, mas realizando o aprendizado da língua mediado pelas TICs.

Com o advento das "novas tecnologias", o ensino de línguas estrangeiras sai do espaço convencional, tem novos atores, faz uso de instrumentos mediáticos que permitem estabelecer uma relação virtual entre professor e aluno. Esta relação precisa ser descrita e analisada, pois pressupomos que, para que o aprendizado ocorra, é necessário estabelecer uma nova relação entre aluno e professor com novas formas de construção de conhecimento. Mesmo que o aluno já esteja ambientado com o ensino a distância, com as ferramentas tecnológicas disponíveis e já tenha desenvolvido o perfil próprio do aluno virtual - autônomo e responsável pela aprendizagem, o aprendizado de uma língua estrangeira nessa modalidade apresenta muitos desafios: a apresentação da língua como código linguístico e como prática social dinâmica, contextualizada e indissociável de uma cultura.

O estudo sobre o ensino de português como língua estrangeira na modalidade a distância pode contribuir não só para ampliar as pesquisas sobre as novas tecnologias e ensino de línguas, mas também poderá colaborar para a expansão do português no mundo, dar maior visibilidade às universidades brasileiras e impulsionar o desenvolvimento do país econômica e socialmente.

\section{REFERÊNCIAS}

BAKHTIN, M. Marxismo e filosofia da linguagem. São Paulo: Hucitec, 1990.

Estética da criação verbal. São Paulo: Martins Fontes, 1992.

BRONCKART, J-P. Interactions, discours, significations. Langue Française (La typologie des discours), n. 74, p. 29-50, 1987.

CHARAUDEAU, Patrick. Primeira parte: Uma problemática semiolinguística do estudo do discurso. In: Linguagem e discurso: modos de organização. São Paulo: Contexto, 2008, pp. $13-63$.

ISENBERG, Horst. Cuestiones fundamentales de tipologia textual. In: Bernardez, Enrique (org.). Linguística del texto. Madrid, Arco libros, 1987, p.97-129.

MARCUSCHI, Luiz Antônio. Fala e escrita: relações vistas num continuum tipológico com especial atenção para os dêiticos discursivos. Texto digitado, apresentado em mesaredonda no II Encontro nacional sobre fala e escrita. Maceió, novembro de 1995. P.1-11. 
PETITJEAN, A. 1989. Les tipologies textuels. Pratiques 62. pp. 86-125 